\title{
Epidemiologia da doença de Chagas em quatro localidades rurais de Jaguaruana, Estado do Ceará. Soroprevalência da infecção, parasitemia e aspectos clínicos
}

\author{
Epidemiology of Chagas disease in four rural localities in Jaguaruana, State of \\ Ceará. Seroprevalence of infection, parasitemia and clinical characteristics
}

\author{
José Borges-Pereira ${ }^{1}$, Otília Sarquis ${ }^{2}$, Patrícia Lago Zauza ${ }^{1}$, \\ Constança Britto ${ }^{3}$ e Marli Maria Lima ${ }^{2}$
}

\begin{abstract}
RESUMO
Um estudo transversal sobre a doença de Chagas realizado com o exame da população de quatro localidades ( $\mathrm{n}^{0}=541$ habitantes) do município de Jaguaruana, Estado do Ceará, mostrou: a soroprevalência da infecção chagásica em 3,1\%, avaliada pelos testes de imunofluorescência indireta, hemaglutinação indireta e ELISA, maior entre as pessoas com mais de 50 anos e sem diferença em relação ao sexo; a parasitemia positiva em 11,8\% (2/17) soropositivos, determinada pelo xenodiagnóstico indireto e em $75 \%(9 / 12)$ pela reação em cadeia da polimerase $(\mathrm{p}<0,05)$; a cardiopatia em $41 \%(7 / 17)$ dos soropositivos e em 11,8\% (2/17) dos controles soronegativos $(\mathrm{p}<0,05)$, avaliada por anamnese, exame físico e eletrocardiograma de repouso. A análise desses resultados mostrou que as prevalências da parasitemia positiva e da cardiopatia chagásica crônica são semelhantes às da Caatinga do Piauí e maiores do que no Sertão da Paraíba, apesar de historicamente, todas essas áreas apresentarem o Triatoma brasiliensis e 0 Triatoma pseudomaculata como principais responsáveis pela transmissão da infecção chagásica.
\end{abstract}

Palavras-chaves: Doença de Chagas. Estudo transversal. Prevalência da infecção. Cardiopatia chagásica. Ceará.

\begin{abstract}
A cross-sectional study on Chagas disease that examined the populations of four localities ( $n^{0}=541$ inhabitants) in the municipality of Jaguaruana, State of Ceará, showed seroprevalence of Chagas infection of $3.1 \%$, as assessed by indirect immunofluorescence, indirect hemagglutination and ELISA tests. The rate was higher among adults over 50 years old, without any difference in relation to sex. Positive parasitemia was found in $11.8 \%(2 / 17)$ of the seropositive individuals by means of indirect xenodiagnosis and in $75 \%(9 / 12)$ by means of the polymerase chain reaction ( $<<0.05)$. Cardiopathy was found by means of anamnesis, physical examination and resting electrocardiogram in $41 \%$ (7/17) of the seropositive individuals and in $11.8 \%$ $(2 / 17)$ of the seronegative controls $(\mathrm{p}<0.05)$. Analysis of these results showed that the prevalences of positive parasitemia and chronic Chagas cardiopathy were similar to those in the Caatinga area of Piauí and greater than in the Sertão area of Paraíba, although all these areas historically presented Triatoma brasiliensis and Triatoma pseudomaculata as the primary vectors responsible for Chagas infection transmission.
\end{abstract}

Key-words: Chagas disease. Cross-sectional study. Seroprevalence of infection. Chagas cardiopathy. Ceará.

A história da doença de Chagas no Estado do Ceará inicia-se em 1911 com o registro de Rhodnius nasutus na serra de Ibiapaba ${ }^{1926}$. Duas décadas depois, foram registrados triatomíneos infectados por Trypanosoma cruzi nas zonas do Cariri e Quixadá25, gatos infectados no município de Russas e Didelphis albiventris infectados no noroeste do estado ${ }^{19}$. Em 1938, na região do baixo
Jaguaribe no Posto das Grandes Endemias, localizado em Russas, identificou-se Triatoma brasiliensis infectado e casos suspeitos de tripanossomíase americana na área investigada. Na década de 40, foram confirmados os primeiros casos de infecção chagásica humana através de xenodiagnósticos ${ }^{129}$ e o primeiro caso típico de cardiopatia chagásica em indivíduo procedente do Município de Quixadáa ${ }^{21}$.

\footnotetext{
1. Laboratório de Doenças Parasitárias, Instituto Oswaldo Cruz, Fundação Oswaldo Cruz, Rio de Janeiro, RJ. 2. Laboratório de Eco-Epidemiologia da Doença de Chagas, Instituto Oswaldo Cruz, Fundação Oswaldo Cruz, Rio de Janeiro, RJ. 3. Laboratório de Biologia Molecular e Doenças Endêmicas, Instituto Oswaldo Cruz, Fundação Oswaldo Cruz, Rio de Janeiro, RJ. Apoio financeiro: CNPq, PAPES-FIOCRUZ e FAPERJ.

Endereço para correspondência: Dr. José Borges-Pereira. Laboratório de Doenças Parasitárias/IOC/FIOCRUZ. Av. Brasil 4365, Pavilhão Arthur Neiva, Sala 17, Manguinhos, 21045-900 Rio de Janeiro, RJ.

e-mail: borges@ioc.fiocruz.br

Recebido para publicação em 21/12/2007

Aceito em 17/07/2008
} 
No primeiro inquérito sorológico realizado no estado, nos arredores de Quixadá, foram examinados 200 indivíduos através da reação de Guerreiro \& Machado, dos quais 17 (8,5\%) apresentaramse positivos ${ }^{22}$. No período 1959-1979, Alencar ${ }^{4}$ realizou diversas pesquisas sobre a prevalência da infecção e distribuição dos triatomíneos no estado, definindo diferentes tipos de micro-regiões em relação à doença de Chagas: a área de maior prevalência de Panstrongylus megistus correspondia à área de maior prevalência de infecção chagásica e de menor extensão geográfica; a área exclusiva de Triatoma brasiliensis correspondia à área de menor prevalência da infecção chagásica e de maior extensão geográfica e a área exclusiva de Triatoma pseudomaculata correspondia à área de menor prevalência da infecção chagásica e de reduzida extensão geográfica. Durante o inquérito sorológico nacional, realizado no período 1975-1980 $0^{14}$, a prevalência da infecção no estado foi estimada em $0,8 \%$ da população rural.

0 ciclo de manutenção da transmissão da infecção chagásica no Estado do Cearáfoi definido por Alencar e cols ${ }^{2345}$ : no ciclo doméstico os principais reservatórios de Trypanosoma cruzi eram os ratos de casa, enquanto no ciclo peridoméstico eram gambás ou cassacos (Didelphis sp). As principais espécies de triatomíneos envolvidas nos ciclos eram: Triatoma brasiliensis, principal espécie transmissora, de hábitos semidomésticos, com taxa de infecção média de 8,2\%; Triatoma pseudomaculata, espécie menos doméstica, com taxa de infecção média de 4,2\%; Panstrongylus megistus apresentando taxa de infecção média de 3,9\%; Rhodnius nasutus com infecção natural de 1\% e Panstrongylus lutzi com taxas de infecção de até 17,9\%. Ressalta-se que não houve referência à captura de Triatoma infestans e Triatoma sordida no território do Estado do Ceará, indicando que essas espécies provavelmente não participaram do ciclo de manutenção da infecção chagásica nessa área do Brasil.

A partir da literatura sobre a doença de Chagas no Estado do Ceará, verifica-se que o município de Jaguaruana sempre esteve no grupo das áreas com as maiores prevalências da infecção chagásica. No início do ano 2000, houve relato de parte da população sobre a presença de triatomíneos em domicílios nas localidades rurais de Currais do Felipe, Figueiredo, Figueiredo do Bruno e Coberto, o que motivou a realização do presente estudo, em colaboração com a secretaria de saúde do município, para avaliar a situação epidemiológica da doença de Chagas nessas localidades e orientar o município para o controle vetorial e manejo da sua população de chagásicos.

\section{MATERIAL E MÉTODOS}

Área de estudo. 0 município de Jaguaruana está localizado na região Leste do Estado do Ceará, a cerca de $180 \mathrm{~km}$ de Fortaleza, capital do estado. 0 presente trabalho foi realizado nas localidades de Coberto, Currais do Felipe, Figueiredo e Figueiredo do Bruno, distantes de 5 a $7 \mathrm{~km}$ da sede do município (Figura 1). Na ocasião do estudo, de março de 2000 a abril de 2002, foram registrados 15 domicílios e 61 habitantes em Coberto, 19 domicílios e 76 habitantes em Currais do Felipe, 83 domicílios e 348 habitantes em Figueiredo e 41 domicílios e 146 habitantes em Figueiredo do Bruno. Essas localidades constituem áreas de planícies de solos argiloso e arenoso, situadas no domínio da Caatinga, tipo de vegetação característica do semi-árido.

Soroprevalência. No período do estudo, foi feita a visita aos domicílios das localidades e realizou-se o censo da população residente. Foram cadastrados 631 moradores, dos quais 541 aceitaram participar das investigações, após informações sobre os riscos e benefícios, enquanto 90 (14,3\%) não participaram por recusas ou ausências no momento da coleta da amostra de sangue. De cada participante, foi colhida amostra de sangue em papel de filtro (Klabin 80) após punção da polpa digital e submetida ao teste de imunofluorescência indireta (IFI) para detecção de IgG anti-Trypanosoma cruzi $^{34}$. No total foram colhidas e examinadas 32 amostras de sangue em Coberto, 76 em Currais do Felipe, 142 em Figueiredo do Bruno e 291 em Figueiredo. Para a confirmação do resultado sorológico da triagem, foram obtidos $5 \mathrm{ml}$ de sangue venoso de indivíduos com IFI positiva e de igual número de indivíduos com IFI negativa pareados por idade e sexo. As amostras de soros foram submetidas ao teste de IFI na diluição de 1:40 (produzido por Bio-Manguinhos), hemaglutinação indireta na diluição de 1:40 (produzido por Biolab) e ELISA (enzyme-linked immunosorbent assay) convencional na diluição de 1:100 (produzido por BioManguinhos). Conforme critérios e orientação da $\mathrm{WHO}^{35}$ para confirmação do diagnóstico sorológico da doença de Chagas, os resultados foram interpretados assim: soronegativo - todos os testes negativos; soro inconclusivo - apenas um teste positivo e soropositivo - dois ou mais testes positivos com técnicas diferentes. 0 número de soropositivos foi utilizado para estimar a soroprevalência.

Parasitemia. Foi realizada através do xenodiagnóstico indireto (XDI) e da técnica da reação em cadeia da polimerase (PCR) em 17 moradores soropositivos e 4 com soros inconclusivos. Foram coletados $20 \mathrm{ml}$ de sangue venoso periférico de cada pessoa: $10 \mathrm{ml}$ para o xenodiagnóstico indireto (XDI) e 10ml para a PCR. No XDI, foi utilizada uma caixa de madeira apropriada com 20 ninfas III e IV de Triatoma brasiliensis e outra caixa com 20 ninfas III e IV de Panstrongylus megistus. Para o repasto das ninfas foi oferecida uma bolsa de látex (condom) contendo $5 \mathrm{ml}$ de sangue heparinizado para cada espécie, durante uma hora em temperatura média ambiente de $28^{\circ} \mathrm{C}$. Quarenta e cinco dias após o repasto, as fezes ou o triturado do tubo digestivo de cada ninfa foram examinados entre lâmina e lamínula, por observação direta a microscópio. Para o teste da PCR, o volume de sangue coletado sem anticoagulante foi imediatamente misturado a $10 \mathrm{ml}$ de solução de guanidina-HCl 6M e EDTA 0.2M (solução de lise) e os tubos com os lisados foram mantidos à temperatura ambiente por no máximo 10 dias, em seguida encaminhados ao Laboratório de Biologia Molecular e Doenças Endêmicas do IOC - FIOCRUZ, para processamento e detecção de k-DNA de Trypanosoma cruzi, conforme Wincker cols ${ }^{36}$ e Britto cols ${ }^{13}$, empregando-se os primers 5-AAATAATGTACGGG(T/G)GAGATGCATGA-3', e 5GGTTGCATTGGGTTGGTGTAATATA-3’, que amplificam o fragmento de 330 pares de bases contendo as regiões hipervariáveis dos minicírculos do DNA do cinetoplasto (k-DNA) do parasita.

Aspectos clínicos e eletrocardiograma. Dezessete moradores soropositivos, 4 soros inconclusivos e 21 soronegativos pareados por sexo e idade foram avaliados através de anamnese 


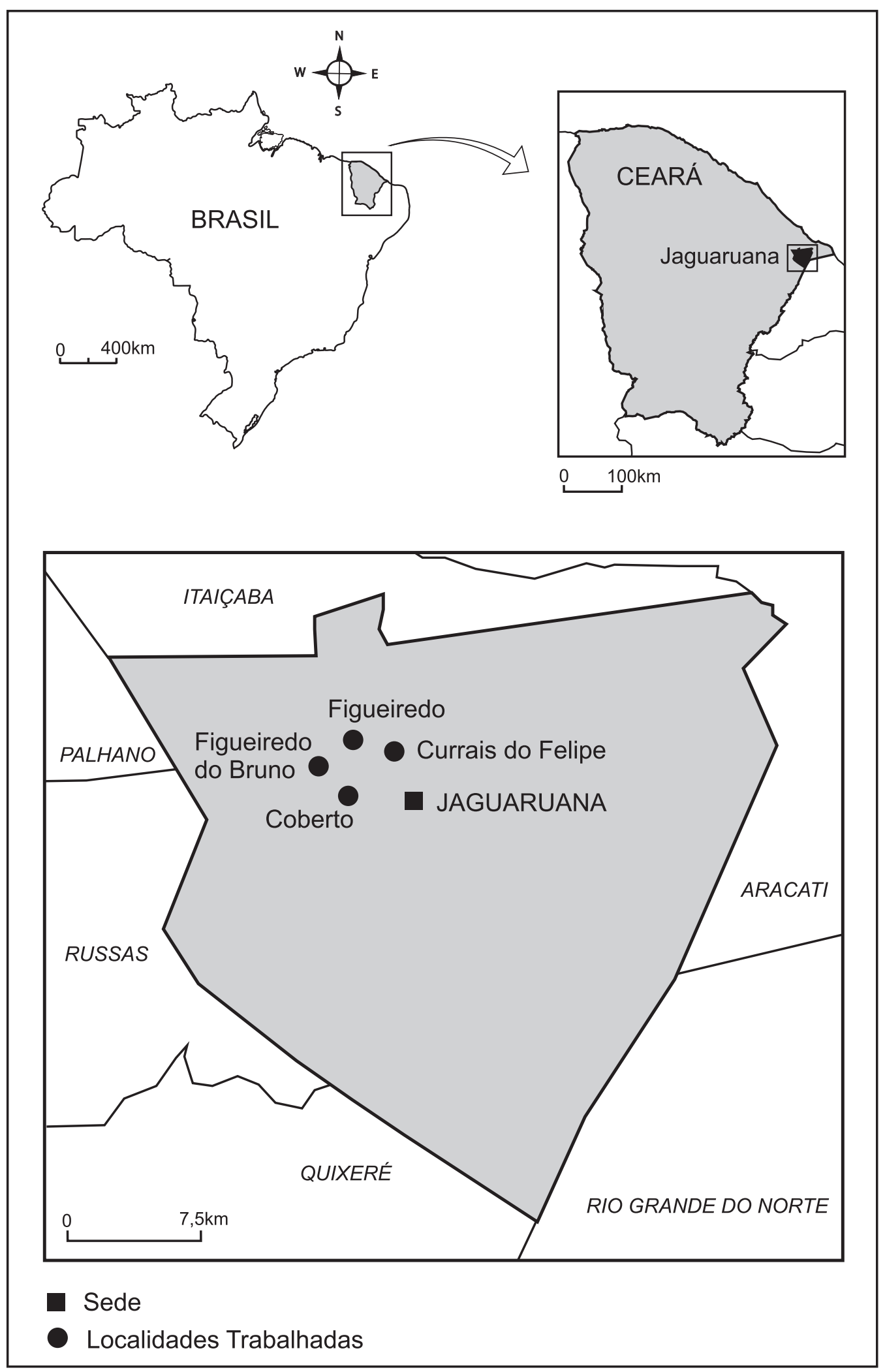

Figura 1 - Localização da área de estudo em Jaguaruana, Ceará.

e exame físico dirigidos para a obtenção de informações acerca de manifestações (sintomas e sinais) ligadas aos aparelhos cardiovascular e digestivo conforme ficha padronizada com base nas recomendações contidas no documento da OPAS $^{27} \mathrm{e}$ eletrocardiograma de repouso, no qual foi obtido o registro das doze derivações clássicas periféricas (D1, D2, D3, aVR, aVL e
aVF) e precordiais (V1 a V6) com o mínimo de três complexos por derivação e D2 longo em caso de arritmias detectadas no exame físico ou durante o registro do traçado. A leitura dos traçados foi feita por dois pesquisadores, utilizando os critérios do Código de Minessota adaptado para o estudo da cardiopatia chagásica crônica. Considerou-se hipertensão 
arterial as medidas em repouso acima de $140 \mathrm{mmHg}$ sistólica e $90 \mathrm{mmHg}$ diastólica ${ }^{33}$.

Ética e estatística. 0 projeto com protocolo número 0139/01 foi aprovado pelo Comitê de Ética em Pesquisas da FIOCRUZ e as pessoas adultas e os responsáveis por menores assinaram o Termo de Consentimento Informado Livre e Esclarecido, conforme a Resolução 196/1996 do Conselho Nacional de Saúde, participando após esclarecimentos dos riscos e benefícios. Utilizando-se os programas Excel eEpi-Info 6.04, foi construído um banco de dados com aspectos demográficos, clínicos, da parasitemia e eletrocardiográficos. Na comparação das variáveis categóricas realizou-se análise univariada, utilizando-se o teste do qui-quadrado ou o teste exato de Fischer, considerando-se o nível de significância de 5\%.

\section{RESULTADOS}

Soroprevalência. Das 541 amostras de sangue coletadas em papel de filtro, 23 apresentaram-se com o teste de imunofluorescência indireta (IFI) positivo para anticorpos antiTrypanosoma cruzi. A sorologia confirmatória foi realizada em soros de 21 pessoas e não realizada em duas que migraram para outra região. Dos soros testados por IFI, hemaglutinação indireta e ELISA, 17 apresentaram-se soropositivos (dois ou mais testes positivos) e quatro apresentaram-se inconclusivos (somente um teste positivo), permitindo a estimativa da soroprevalência da infecção chagásica em 3,1\% (17/541); sem diferença significativa em relação ao sexo $\left(X^{2}=0,62 ; \mathrm{p}=0,61 ; \mathrm{g}=1\right)$, mas com valores crescentes em função da faixa etária $\left(X^{2}=0,01 ; p=15,56\right.$; $\mathrm{gl}=6$ ), sem registro de soropositividade em menores de 16 anos
(Tabela 1). A distribuição da prevalência da infecção nas localidades foi a seguinte: 1,3\% (1/76) em Currais do Felipe, 1,7\% (5/291) em Figueiredo, 6,3\% (2/32) em Coberto e 6,3\% (9/142) em Figueiredo do Bruno. No grupo controle, os soros das 21 pessoas pareadas apresentaram-se negativos nas três modalidades de testes sorológicos realizados.

Parasitemia. Das 17 pessoas soropositivas submetidas ao xenodiagnóstico indireto, apenas duas (11,8\%) apresentaram o exame positivo com infecção de ninfas de Triatoma brasiliensis, ambas moradoras da localidade de Figueiredo do Bruno, ressaltando o baixo índice de ninfas alimentadas (25\%) entre as aplicadas no repasto, enquanto a PCR realizada em 12 pessoas mostrou-se positiva em 9 (75\%) (Tabela 2). As quatro pessoas com soros inconclusivos apresentaram-se com xenodiagnóstico e

Tabela 1 - Soropositividade* para anticorpos anti-Trypanosoma cruzi, por faixa etária e sexo, em moradores das localidades de Coberto, Currais do Felipe, Figueiredo do Bruno e Figueiredo, Jaguaruana, CE, 2002.

\begin{tabular}{|c|c|c|c|c|c|c|c|c|c|}
\hline \multirow{2}{*}{$\begin{array}{l}\text { Faixa etária } \\
\text { (anos) }\end{array}$} & \multicolumn{3}{|c|}{ Mulheres } & \multicolumn{3}{|c|}{ Homens } & \multicolumn{3}{|c|}{ Total } \\
\hline & $\overline{\text { exa }}$ & pos & $\%$ pos & exa & pos & $\%$ pos & exa & pos & $\%$ pos \\
\hline $0-9$ & 58 & 0 & - & 54 & 0 & - & 112 & 0 & - \\
\hline $10-19$ & 65 & 1 & 1,5 & 56 & 0 & - & 121 & 1 & 0,8 \\
\hline $20-29$ & 44 & 2 & 4,5 & 52 & 1 & 1,9 & 96 & 3 & 3,1 \\
\hline 30-39 & 39 & 1 & 2,5 & 33 & 3 & 9,1 & 72 & 4 & 5,5 \\
\hline $40-49$ & 31 & 0 & - & 17 & 0 & - & 48 & 0 & - \\
\hline $50-59$ & 17 & 2 & 11,8 & 15 & 0 & - & 32 & 2 & 6,3 \\
\hline $60-69$ & 14 & 2 & 14,3 & 12 & 1 & 8,3 & 26 & 3 & 11,5 \\
\hline$\geq 70$ & 18 & 2 & 11,1 & 16 & 2 & 12,5 & 34 & 4 & 11,8 \\
\hline Total & 286 & 10 & 3,5 & 255 & 7 & 2,7 & 541 & 17 & 3,1 \\
\hline
\end{tabular}

*determinada pelos testes de IFI, HAI e ELISA em soros, exa: examinados, pos: positivos.

Tabela 2 - Dados demográficos, sorológicos, parasitológicos, clínicos e eletrocardiográficos de 21 moradores de quatro localidades de Jaguaruana, Ceará, 2002, com sorologia positiva e inconclusiva para doença de Chagas.

\begin{tabular}{|c|c|c|c|c|c|c|c|c|c|c|c|c|}
\hline Localidade & Registro & Nome & Idade & Sexo & IFI & HAI & ELISA & $\begin{array}{c}\text { Sorologia } \\
\text { confirmatóiria }\end{array}$ & XDI & PCR & Clínica & Eletrocardiograma \\
\hline Figueiredo & 40 & JIP & 54 & M & + & - & - & Inconclusiva & - & - & Assintomática & Normal \\
\hline Figueiredo & 43 & APRP & 26 & $\mathrm{~F}$ & + & - & - & Inconclusiva & - & - & Assintomática & Normal \\
\hline Figueiredo & 53 & MLS & 40 & $\mathrm{~F}$ & + & - & - & Inconclusiva & - & - & Assintomática & Normal \\
\hline Figueiredo & 55 & FCS & 22 & $\mathrm{~F}$ & + & - & + & Positiva & - & + & Assintomática & Normal \\
\hline Figueiredo do Bruno & 56 & JBS & 34 & M & + & + & + & Positiva & - & NR & Assintomática & Normal \\
\hline Figueiredo do Bruno & 58 & MBS & 74 & $\mathrm{~F}$ & + & + & + & Positiva & - & + & Assintomática & Normal \\
\hline Figueiredo do Bruno & 59 & JMF & 78 & M & + & + & - & Positiva & - & - & Sintomática & EVF \\
\hline Figueiredo do Bruno & 60 & JMM & 33 & M & + & + & + & Positiva & - & + & Sintomática & BRD III + HBAE \\
\hline Figueiredo & 102 & ARA & 16 & $\mathrm{~F}$ & + & + & + & Positiva & - & NR & Assintomática & Normal \\
\hline Currais do Felipe & 157 & FSS & 82 & M & + & + & + & Positiva & - & NR & Sintomática & EVF \\
\hline Coberto & 212 & MSB & 32 & $\mathrm{~F}$ & + & + & + & Positiva & - & NR & Sintomática & Normal \\
\hline Figueiredo do Bruno & 233 & RGS & 59 & $\mathrm{~F}$ & + & + & + & Positiva & - & + & Sintomática & $\mathrm{EV}$ \\
\hline Coberto & 245 & RBS & 61 & $\mathrm{~F}$ & + & + & + & Positiva & - & NR & Assintomática & Normal \\
\hline Figueiredo do Bruno & 247 & RRBP & 71 & $\mathrm{~F}$ & + & + & + & Positiva & - & + & Sintomática & APRV \\
\hline Figueiredo & 257 & VPR & 27 & M & + & + & + & Positiva & + & + & Assintomática & Normal \\
\hline Figueiredo do Bruno & 388 & FCO & 33 & M & + & + & + & Positiva & - & + & Assintomática & Normal \\
\hline Figueiredo do Bruno & 396 & MGCS & 55 & $\mathrm{~F}$ & + & + & + & Positiva & - & + & Assintomática & Normal \\
\hline Figueiredo do Bruno & 409 & ARO & 65 & M & + & + & + & Positiva & - & - & Sintomática & BAV III-MP \\
\hline Figueiredo & 610 & MGJ & 63 & $\mathrm{~F}$ & + & + & + & Positiva & + & + & Sintomática & EVF \\
\hline Figueiredo & 634 & $\mathrm{MGA}$ & 22 & $\mathrm{~F}$ & + & + & + & Positiva & - & - & Assintomática & Normal \\
\hline Figueiredo & 653 & MEO & 55 & $\mathrm{~F}$ & - & - & + & Inconclusiva & - & - & Assintomática & Normal \\
\hline
\end{tabular}

IFI: imunofluorescência indireta, HAI: hemaglutinação indireta, ELISA: enzyme-linked immunosorbent assay, XDI: xenodiagnóstico indireto, PCR: reação em cadeia da polimerase., M: masculino, F: feminino, NR: não realizado. EVF: extra-sístole ventricular freqüente (> 2/min); BRD III + HBAE: bloqueio completo do ramo direito + hemibloqueio anterior esquerdo, EV: extra-sístole ventricular, APRV: alteração primária da repolarização ventricular, BAV III-MP: bloqueio aurículo-ventricular completo, em uso de marca-passo. 
PCR negativos. Esses exames não foram realizados nas 21 pessoas soronegativas do grupo controle.

Exame clínico e ECG. No grupo das 17 pessoas soropositivas, 7 (41,2\%) apresentaram sintomatologia cardiovascular, representada por palpitações $\left(n^{0}=6\right)$ e dispnéia aos esforços $\left(n^{0}=4\right)$ e $2(11,8 \%)$ apresentaram sintomatologia digestiva representada por disfagia, uma delas com antecedente de cirurgia do megaesôfago, enquanto no grupo controle $2(11,8 \%)$ pessoas referiram palpitações. A hipertensão arterial foi registrada em $3(17,6 \%)$ pessoas soropositivas e em $3(17,6 \%)$ controles soronegativas. O eletrocardiograma alterado foi registrado em 7 (41,2\%) pessoas soropositivas e em 2 (11,8\%) controles soronegativas. As alterações no grupo de soropositivas estão assinaladas na Tabela 2, enquanto no grupo controle, um ECG apresentou-se com sobrecarga ventricular esquerda e outro com alteração primária da repolarização ventricular. As quatro pessoas com sorologia inconclusiva apresentaram-se assintomáticas e com ECG normal (Tabela 2).

\section{DISCUSSÃo}

A presença de triatomíneos nas quatro localidades pesquisadas foi confirmada nas investigações de Sarquis cols ${ }^{31}$. Esses autores capturaram, em intra e peridomicílios, exemplares de Triatoma brasiliensis, Triatoma pseudomaculata, Rhodnius nasutus e Panstrongylus lutzi. Dentre estas espécies, Triatoma brasiliensis apresentou a maior $(74,8 \%)$ prevalência, seguido de Triatoma pseudomaculata e de Rhodnius nasutus; Panstrongylus lutzi foi capturado em bem menor proporção e apenas adultos. Na definição dos ecótopos preferenciais, Sarquis cols ${ }^{32}$ registraram a maior captura de Triatoma brasiliensis em abrigos de animais domésticos, cobertos com telhas; Triatoma pseudomaculata e Rhodnius nasutus preferiram poleiros e madeiras de abrigos de animais cobertos com palhas. Esta última espécie foi capturada também nas copas das carnaubeiras, seu habitat natural. Como conseqüência desses estudos, 18 cepas de Trypanosoma cruzi foram isoladas de triatomíneos naturalmente infectados e analisadas por MLEE (multilocus enzyme electrophoresis) e RAPD (randomly amplified polymorphic DNA), sendo caracterizadas como variantes do zimodema Z1 (Tc I) ${ }^{11}$.

A prevalência da infecção chagásica de 3,1\% entre os moradores das quatro localidades é significativamente inferior ao valor de 6,1\% estimado para a população rural do município durante o inquérito sorológico nacional realizado em 1975-1980 ${ }^{14}$, indicando uma queda na prevalência da infecção, configurada principalmente pela ausência de infecção em menores de 16 anos no presente estudo. Esse comportamento na prevalência da infecção foi observado no inquérito sorológico realizado em todo o Estado do Piauí, também em $2002^{8}$, indicando essa tendência de redução na prevalência da infecção como produto das medidas de controle da transmissão vetorial, principalmente no intradomicílio, implantadas no território brasileiro. Por outro lado, a prevalência da infecção das localidades mantém a região do Baixo Jaguaribe entre aquelas com maiores índices de infecção no Estado do Ceará.
Não houve diferença significativa na prevalência da infecção em relação ao sexo e até o momento o conhecimento sobre a dinâmica da transmissão nessa área não nos permite explicar esse achado. Em áreas endêmicas como Virgem da Lapa ${ }^{10} \mathrm{e} \mathrm{Berilo}^{6} \mathrm{em}$ Minas Gerais e em Mambai ${ }^{15}$ em Goiás, nas quais a transmissão vetorial ocorreu essencialmente no intradomicílio, a prevalência da infecção é maior no grupo de mulheres. Por outro lado, a prevalência da infecção pode esta relacionada com a atividade profissional do indivíduo como foi demonstrado por Coura cols ${ }^{17}$ nos piaçabais da região de Barcelos-Amazonas. A ausência de menores de 16 anos soropositivos na área é um indicador de inatividade da transmissão vetorial, provavelmente em decorrência da eficácia das medidas de controle implementadas, enquanto a ausência de pessoas soropositivas de 40 a 49 anos (Tabela 1) pode ser o produto da maior freqüência de óbitos entre chagásicos com cardiopatia crônica ${ }^{610}$. A maior prevalência da infecção chagásica na localidade de Figueiredo do Bruno associou-se à maior densidade de triatomíneos no intradomicílio, principalmente Triatoma brasiliensis, e ao elevado índice de infecção natural por Trypanosoma cruzi encontrados por Sarquis ${ }^{29}$.

A não confirmação do diagnóstico sorológico através dos testes de HAI e ELISA em quatro pessoas com IFI positiva no eluato de sangue e no soro (Tabela 2) indica-nos a presença de reação cruzada na área de estudo, relacionada principalmente com a detecção de anticorpos dirigidos aos antígenos de superfície do Trypanosoma cruzi. Os resultados falso-positivos têm sido uma observação frequiente em regiões com baixa prevalência da infecção chagásica como no Distrito Sanitário de Rio Verde em Mato Grosso do Sul ${ }^{12}$ e áreas de colonização agrícola em Roraima ${ }^{23}$, assim como em áreas com significativa redução da prevalência da infecção em menores de 20 anos, a exemplo de Virgem da Lapa ${ }^{10}$ e Berilo ${ }^{6}$ no Vale do Jequitinhonha, Minas Gerais. Esse fenômeno merece bastante atenção para não superdimensionar os valores da soroprevalência de uma área, influindo sobremaneira nas decisões da vigilância epidemiológica.

A parasitemia positiva na população chagásica crônica de uma área com elevada densidade de triatomíneos, naturalmente infectados pelo Trypanosoma cruzi, constitui-se em risco de instalação do ciclo de transmissão vetorial, caso a vigilância epidemiológica não seja permanente. Na população estudada consideramos baixa a positividade do xenodiagnóstico, que atribuímos ao baixo índice de ninfas alimentadas. Por outro lado, a positividade da reação em cadeia da polimerase em 75\% assemelha-se aos valores encontrados em áreas do Piauí , nas quais os principais vetores são das mesmas espécies que os das localidades estudadas. A medida da parasitemia pelo xenodiagnóstico e da morbidade na fase crônica da doença de Chagas tem sido feita em estudos seccionais e longitudinais de coortes $^{151628}$, os quais não têm revelado associação entre ambas. Entretanto, com a introdução da técnica da PCR, mais sensível no diagnóstico parasitológico, observa-se uma correlação positiva entre morbidade e parasitemia. Coura cols ${ }^{18}$ analisando os resultados obtidos em diferentes áreas do Brasil mostram que em Virgem da Lapa-MG e João Costa-PI, com positividade da PCR acima de $70 \%$, a prevalência de cardiopatia chagásica crônica 
está em torno de 30\%, já em municípios do Sertão da Paraíba ${ }^{13}$ e no Distrito Sanitário de Rio Verde-MS ${ }^{12}$, onde a positividade da PCR é inferior a 70\%, a prevalência da cardiopatia chagásica está em torno de $20 \%$.

A cardiopatia e esofagopatia na população chagásica estudada foram confirmadas pela presença de manifestações clínicas cardiovasculares e digestivas, ECG alterado e o antecedente de cirurgia de megaesôfago. Apesar do pequeno número de pessoas avaliadas, a ocorrência de alterações eletrocardiográficas sugestivas da cardiopatia chagásica crônica associada à proporção de ECG alterado atribuído à etiologia chagásica em torno de $30 \%$ situa a morbidade cardíaca da área no mesmo patamar das áreas estudadas no Estado do Piauî ${ }^{16}$ e bem maior que a prevalência estimada para o Estado do Ceará a partir do inquérito eletrocardiográfico nacional realizado por Macedo $\operatorname{cols}^{24}$. Por outro lado, a taxa de mortalidade por doença de Chagas no Estado do Ceará, segundo análise dos dados do DATASUS de $1998^{20}$, é quatro vezes menor do que a taxa do Estado do Piauí e duas vezes maior do que a taxa do Estado da Paraíba, configurando-se significativa variação regional na gravidade da patologia chagásica.

Como perspectivas do presente trabalho, a pesquisa está sendo intensificada através da investigação de outras localidades rurais de Jaguaruana, com o principal objetivo de definir se os zimodemas de cepas de Trypanosama cruzi circulantes entre as pessoas chagásicas crônicas são similares aos zimodemas Z1 isolados dos triatomíneos capturados nas mesmas localidades. 0 aumento da população de estudo permitirá também compor uma coorte com maior representatividade que permita estudos longitudinais sobre as prevalências de cardiopatia e de megaesôfago chagásicos na zona rural do município.

\section{AGRADECIMENTOS}

Agradecemos aos técnicos José de Souza Nogueira e Júlio César Miguel, do Laboratório de Doenças Parasitárias do Instituto Oswaldo Cruz, pelo auxílio na coleta e preservação das amostras de sangue, montagem, aplicação e leitura dos xenodiagnósticos. Aos agentes de saúde e técnicos de enfermagem do município de Jaguaruana pelo auxílio na convocação e no exame clínico das pessoas. À Prefeitura de Jaguaruana e Secretaria de Saúde do Estado do Ceará, pelo apoio logístico.

\section{REFERÊNCIAS}

1. Albuquerque AFR, Brito RS, Morais NO. Importante foco de mal de Chagas e leishmaniose visceral americana no Vale do Cariri (Estados do Ceará e Pernambuco). 0 Hospital 2:61-69, 1942.

2. Alencar JE. Estudos sobre a epidemiologia da doença de Chagas no Ceará. I - dados preliminares. Revista Brasileira de Malariologia e Doenças Tropicais 14:201-219, 1962.

3. Alencar JE. Estudos sobre a epidemiologia da doença de Chagas no Ceará. III - Região do Baixo Jaguaribe. Revista Brasileira de Malariologia e Doenças Tropicais 17:149-158, 1965.

4. Alencar JE. História natural da doença de Chagas no Estado do Ceará. Imprensa Universitária da Universidade Federal do Ceará. Fortaleza, Ceará, 1987
5. Alencar JE, Almeida JO, Sherlock V, França AP, Leite L. Estudos sobre a epidemiologia da doença de Chagas no Ceará. II - Novos dados. Revista Brasileira de Malariologia e Doenças Tropicais 15:551-565, 1963.

6. Araújo RM. Morbidade da doença de Chagas no município de Berilo, Minas Gerais. Estudos seccional e evolutivo de 10 anos (1987-1997). Tese de doutorado. Instituto Oswaldo Cruz, Fundação Oswaldo Cruz, Rio de Janeiro, RJ, 1998.

7. Borges-Pereira J, Castro JAF, Campos JHF, Nogueira JS, Zauza PL, Marques P, Cardoso MA, Britto C, Araújo AJG. Estudo da infecção e morbidade da doença de Chagas no município de João Costa: Parque Nacional Serra da Capivara, Piauí, Brasil. Revista da Sociedade Brasileira de Medicina Tropical 35:315-322, 2002.

8. Borges-Pereira J, Castro JAF, Silva AR, Zauza PL, Bulhões TP, Gonçalves ME, Almeida ES, Salmito MA, Pereira LRM, Alves-Filho FI, Correia-Lima FG, Coura JR. Soroprevalência da infecção chagásica no Estado do Piauí, 2002. Revista da Sociedade Brasileira de Medicina Tropical 39:530-539, 2006.

9. Borges-Pereira J, Coura JR. Morbidade da doença de Chagas. Estudo seccional em uma área endêmica, Virgem da Lapa, Minas Gerais. Revista da Sociedade Brasileira de Medicina Tropical 19:139-148, 1986.

10. Borges-Pereira J, Coura JR. Morbidade da doença de Chagas em populações urbanas do sertão da Paraíba. Revista da Sociedade Brasileira de Medicina Tropical 20:101-107, 1987.

11. Borges-Pereira J, Willcox HPF, Coura JR. Evolução da cardiopatia chagásica crônica. I - Influência da Parasitemia. Revista da Sociedade Brasileira de Medicina Tropical 25:101-108, 1992.

12. Borges-Pereira J, Zauza PL, Galhardo MC, Nogueira JS, Pereira GROL, Cunha RV. Doença de Chagas na população urbana do distrito sanitário de Rio Verde, Mato Grosso do Sul, Brasil. Revista da Sociedade Brasileira de Medicina Tropical 34:459-466, 2001.

13. Britto C, Cardoso MA, Ravel C, Santoro A, Borges-Pereira J, Coura JR, Morel CM, Wincker P. Trypanosoma cruzi: Parasite detection and strain discrimination in chronic chagasic patients from Northeastern Brazil using PCR amplification of kinetoplast DNA and nonradiactive hybridization. Experimental Parasitology 81:462-471, 1995.

14. Camargo ME, Silva JR, Castilho EA, Silveira AC. Inquérito sorológico da prevalência da infecção chagásica no Brasil, 1975-1980. Revista do Instituto de Medicina Tropical de São Paulo 26:192-204, 1984.

15. Castro CN. Influência da parasitemia no quadro clínico da doença de Chagas crônica. Revista de Patologia Tropical 9:73-136, 1980.

16. Coura JR, Abreu LL, Dubois LEG, Correia-Lima F, Arruda Jr ER, Willcox HPF, Anunziato N, Petana W 1984. Morbidade da doença de Chagas. II - Estudos seccionais em quatro áreas de campo no Brasil. Memórias do Instituto Oswaldo Cruz 79:101-124, 1984.

17. Coura JR, Arboledo-Naranjo M, Willcox HPF. Chagas disease in the Brazilian Amazon. III. A serological survey. Revista do Instituto de Medicina Tropical de São Paulo 37:103-107,1995.

18. Coura JR, Borges-Pereira J. Araújo RM. Morbidity and regional variation of Chagas disease in Brazil. Memórias do Instituto Oswaldo Cruz 94: (supl II): 26-27, 1999

19. Deane LM, Deane MP. Notas sobre transmissores e reservatórios do Trypanosoma cruzi no noroeste do Estado do Ceará. Revista Brasileira de Malariologia e Doenças Tropicais 9:577-595, 1957.

20. Dias JCP, Machado EMM, Fernandes AL, Vinhaes MC. Esboço geral e perspectivas da doença de Chagas no Nordeste do Brasil. Cadernos de Saúde Pública 16 (supl 2):13-34, 2000.

21. Jucá AQ. Cardiopatia chagásica no Ceará. Medicina, Cirurgia e Farmácia 159:399400, 1949.

22. Jucá AQ, Cunha RV. Contribuição ao estudo da doença de Chagas no Ceará. Ceará Médico 29:36-38,1950.

23. Luitgards-Moura JF, Borges-Pereira J, Costa J, Zauza PL, Rosa-Freitas MG. On the possibility of autochthonous Chagas disease in Roraima, Amazon Region, Brazil, 2000-2001. Revista do Instituto de Medicina Tropical de São Paulo 47:45-54, 2005.

24. Macedo V, Prata A, Silva GR, Castilho E. Prevalência de alterações eletrocardiográficas em chagásicos. (Informações preliminares sobre 0 Inquérito Eletrocardiográfico Nacional). Arquivos Brasileiros de Cardiologia 38:261-264, 1982. 
25. Machado H, Pinto OS. Contribuição ao conhecimento da distribuição geográfica dos triatomíneos domiciliados e de seus índices de infecção natural no Estado do Ceará, Brasil. Revista Brasileira de Malariologia e Doenças Tropicais 4:157-170, 1952.

26. Neiva A. Contribuição ao estudo dos hematophagos brazileiros e descrição de uma nova espécie de Triatoma. Brasil Médico 25:461-462, 1911.

27. Organización Panamericana de la Salud. Aspectos clínicos de la enfermedad de Chagas. Informe de una reunión conjunta OMS/OPAS de investigadores. Boletín de la Oficina Sanitaria Panamericana 76:141-155, 1974

28. Pacheco RS, Brito CMM, Sarquis 0, Pires MQ, Borges-Pereira J, Lima MM. Genetic typing of Trypanosoma cruzi from naturally infected triatomines captured in rural areas of Jaguaruana municipality, Ceará, Brazil. Biochemical Genetics 43:519-530, 2005.

29. Pondé R, Mangabeira Filho 0, Jansen G. Alguns dados sobre leishmaniose visceral americana e doença de Chagas no Nordeste brasileiro. Memórias do Instituto Oswaldo Cruz 37:333-352, 1942.

30. Sarquis 0. Aspectos epidemiológicos da doença de Chagas na zona rural de Jaguaruana, Ceará, Brasil. Tese de doutorado. Instituto Oswaldo Cruz, Fundação Oswaldo Cruz, Rio de Janeiro, RJ, 2003.
31. Sarquis 0, Borges-Pereira J, Mac Cord JR, Gomes TF, Cabello PH, Lima MM. Epidemiology of Chagas Disease in Jaguaruana, Ceará, Brazil: I. Presence of Triatomines and Index of Trypanosoma cruzi Infection in Four Localities of Rural Area. Memórias do Instituto Oswaldo Cruz 99:263-270, 2004.

32. Sarquis 0, Sposina R, Oliveira TG, Mac Cord JR, Cabello PH, Borges-Pereira J, Lima MM. Aspects of peridomiciliary ecotopes in rural areas of Northeastern Brazil associated to triatomine (Hemiptera, Reduviidae) infestation, vectors of Chagas disease. Memórias do Instituto Oswaldo Cruz 101:143-147, 2006.

33. Sociedade Brasileira de Cardiologia. IV. Diretrizes Brasileiras de Hipertensão Arterial. Arquivos Brasileiros de Cardiologia 82 (supl IV):7-14, 2004.

34. Souza SL, Camargo ME. The use of filter paper blood smear in a practical fluorescent test for American Trypanosomiasis serodiagnosis. Revista do Instituto de Medicina Tropical de São Paulo 8:255-258, 1966.

35. World Health Organization. Control of Chagas Disease. Technical Report Series 811, Geneva. 1991.

36. Wincker P, Britto C, Borges-Pereira J, Cardoso MA, Oelemann W, Morel CM. Use of a simplified polymerase chain reaction procedure to detect Trypanosoma cruzi in blood samples from chronic chagasic patients in a rural endemic area. The American Journal of Medicine Tropical and Hygiene 51:771-777, 1994. 